\title{
Optimal Pubertal Induction in Girls with Turner Syndrome Using Either Oral or Transdermal Estradiol: A Proposed Modern Strategy
}

\author{
Malcolm Donaldson ${ }^{a}$ Berit Kriström ${ }^{b}$ Carina Ankarberg-Lindgren ${ }^{c}$ \\ Siska Verlinde ${ }^{d} \quad$ Janiëlle van Alfen-van der Velden ${ }^{e} \quad$ Aneta Gawlik $^{f}$ \\ Marleen M.H.J. van Gelderg Theo Sas ${ }^{\text {h, } i}$ on behalf of the European Society for \\ Paediatric Endocrinology Turner Syndrome Working Group \\ ${ }^{a}$ Glasgow University School of Medicine, Glasgow, UK; ${ }^{b}$ Institution of Clinical Science, Pediatrics, Umeå University, \\ Umeå, Sweden; ' Department of Pediatrics, Institute of Clinical Sciences, Sahlgrenska Academy, University of \\ Gothenburg, Göteborg, Sweden; ${ }^{\mathrm{d} B e l g i a n}$ Study Group of Paediatric Endocrinology and Diabetes, Brussels, \\ Belgium; 'Amalia Children's Hospital, Radboud University Medical Center, Nijmegen, The Netherlands; ${ }^{\text {}}$ Department \\ of Pediatrics and Pediatric Endocrinology, School of Medicine in Katowice, Medical University of Silesia, Katowice, \\ Poland; ${ }^{9}$ Department for Health Evidence, Radboud Institute for Health Sciences, Radboud University Medical

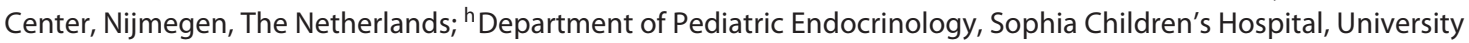 \\ Medical Center Rotterdam, Rotterdam, The Netherlands; ' Diabeter, National Diabetes Care and Research Center, \\ Rotterdam, The Netherlands
}

\section{Keywords}

Turner syndrome · Puberty · $17 \beta$-estradiol · Oral induction · Transdermal induction

\begin{abstract}
Background: Most girls with Turner syndrome (TS) require pubertal induction with estrogen, followed by long term replacement. However, no adequately powered prospective studies comparing transdermal with oral $17 \beta$-estradiol administration exist. This reflects the difficulty of securing funding to study a rare condition with relatively low morbidity/mortality when competing against conditions such as cancer and vascular disease. Protocol Consensus: The TS Working Group of the European Society for Paediatric Endocrinology (ESPE) has agreed to both a 3-year oral and a 3-year transdermal regimen for pubertal induction. Prerequisites
\end{abstract}

(c) 2019 S. Karger AG, Basel

\section{KARGER}

E-Mail karger@karger.com www.karger.com/hrp include suitable $17 \beta$-estradiol tablets and matrix patches to allow the delivery of incremental doses based on body weight. Study Proposal: An international prospective cohort study with single centre analysis is proposed in which clinicians and families are invited to choose either of the agreed regimens, usually starting at 11 years. We hypothesise that pubertal induction with transdermal estradiol will result in better outcomes for some key parameters. The primary outcome measure chosen is height gain during the induction period. Analysis: Assessment of the demographics and drop-out rates of patients choosing either oral or transdermal preparations; and appropriate analysis of outcomes including pubertal height gain, final height, liver enzyme and lipid profile, adherence/acceptability, cardiovascular health, including systolic and diastolic blood pressure and aortic root diameter and bone health. Conclusion: The proposed model of prospective data collection according to in- 
ternationally agreed protocols aims to break the current impasse in obtaining evidence-based management for TS and could be applied to other rare paediatric endocrine conditions.

(c) 2019 S. Karger AG, Basel

\section{Background}

Cardinal features of Turner syndrome (TS) include short stature and primary ovarian insufficiency (POI), accompanied by typical phenotypic traits and a variety of associated cardiac and renal malformations in a minority $[1,2]$. Estrogen induction of puberty is usually required in TS, a retrospective Italian study showing that only 84 of $522(16.1 \%)$ patients achieved spontaneous menarche [3].

TS has long-term health consequences with a significant increase in morbidity [4] and mortality [5]. Cardiovascular disease is particularly important and includes problems such as hypertension, atheroma and aortic dissection [6-8] (especially in girls with previously repaired aortic coarctation or biscupid aortic valve [9]), and risk of metabolic syndrome [10].

Recent attention has focused on sex hormone replacement in POI. The European Society of Human Reproduction and Embryology has developed clinical practice guidelines for the management of women with POI [11]. Clinical practice guidelines for the care of girls and women with TS were published after the International TS Meeting in Cincinnati [12]. Matthews et al. [13] from the United Kingdom have described a consensus from the British Society for Paediatric Endocrinology and Diabetes on hormone supplementation for pubertal induction in girls. Christin-Maitre [14] published a review on the use of hormone replacement in females with endocrine disorders. However, the Cincinnati guidelines do not cover pubertal induction in depth while other papers do not deal specifically with TS.

While transdermal estradiol treatment has strong theoretical advantages over oral treatment and has been used in Sweden for decades [15], the evidence for any superiority is lacking. Matthews et al. [13] write, "There is a real paucity of carefully constructed, randomised controlled clinical trials in girls undergoing induction of puberty. The evidence base is derived mainly from expert experience, a small number of observational studies and very few controlled trials on small study populations. In addition, studies of treatment acceptability and patient adherence are lacking [13]". Thus, while transdermal estradiol may be superior to oral ethinylestradiol in terms of car- diac, bone and uterine health in POI [16-18], adequately powered studies are needed to address these as well as other elements such as growth during pubertal induction, adherence and acceptability [19].

The lack of data on estrogen replacement therapy in TS is partly explained by its relatively low prevalence. TS affects 1 per 2-2,500 of live female births [20] so that in a country such as the United Kingdom only around 150 girls with TS will be born each year. Also, although TS has important implications for morbidity and mortality, this is not on the scale seen in conditions such as cancer, diabetes, ischaemic heart disease, cerebrovascular disease and obesity. Consequently, it is difficult to compete for funding against disorders that are more common, more life-threatening or both.

In this paper, we set out to resolve the current impasse in obtaining evidence-based data on pubertal induction in TS by proposing a novel strategy involving consensus for oral and transdermal protocols; and a prospective cohort study to compare outcomes between the 2 regimens.

\section{Consensus and Strategies Proposed by the Turner Syndrome Working Group of the European Society for Paediatric Endocrinology}

The European Society for Paediatric Endocrinology (ESPE) Turner Syndrome Working Group (TSWG) was formed in 2005 by Professor Catherine Dacou-Voutetakis and meets annually at the main ESPE conference. TSWG comprises 29 members, 6 of whom serve on the Steering Committee. At the annual ESPE meeting in Paris 2016 the group resolved to reach consensus on both oral and transdermal estradiol induction protocols that could be offered to clinicians and families in different countries; and to propose a prospective cohort study in which these protocols were implemented and compared. Between December 2016 and June 2018, members of the Steering Committee held regular telephone and Skype conferences to recommend the following protocols, prospective data collection and strategies for comparing and analyzing data:

- Study hypothesis and outcome measures

- Design of proposed prospective cohort study

- Recommended oral and transdermal $17 \beta$-estradiol regimens for pubertal induction

- Recommended progestogen regimen

- Concurrent growth hormone $(\mathrm{GH})$ and Oxandrolone treatment

- Data collection before and during pubertal induction

- Evaluation of outcomes 


\section{Study Hypothesis}

Based on the available data, it was hypothesized that induction of puberty using transdermal estradiol would result in better outcomes for some key parameters including growth, cardiovascular and bone health, liver function, and lipid profile. The primary outcome measure selected was increase in height $(\mathrm{cm})$ during the 3-year induction period (see below).

\section{Design of Proposed Prospective Cohort Study}

Participating clinicians would counsel girls with TS and their families and help them make an informed choice regarding either of the agreed oral or transdermal regimens for pubertal induction shown below. Although choice will depend partly on the availability of the recommended transdermal or oral $17 \beta$-estradiol preparations, it was felt that clinicians are entitled to request appropriate, guideline-compliant treatment from their hospitals and pharmacies $[12,13]$. In the event of a family choosing either of the proposed regimens, written informed consent would be requested by the clinician for data before, during and after pubertal induction to be sent to a designated European centre and entered into an independent ESPE-approved database under the supervision of an ESPE TSWG member trained in Good Clinical Practice.

Participating centres would need to follow their national regulatory procedure and gain ethical approval for patients and families to give written consent, allowing anonymised data to be sent to the designated host centre and entered on a database for analysis. Since the proposal is not a randomised clinical trial, but an observational cohort study, there would be no need for it to be registered as the former. Any medications given for pubertal induction would be prescribed and funded in the usual way for the country concerned.

\section{Agreed Protocols for Oral and Transdermal $17 \beta$-Estradiol Induction of Puberty in TS}

TSWG agreed that initiation of treatment should normally begin at between 11 and 12 years, consistent with the Cincinnati and UK guidelines $[12,13]$, to mimic normal puberty and facilitate positive psychosocial and psychosexual adaptation in girls with evidence of POI. A serum FSH cut-off of $\geq 10 \mathrm{IU} / \mathrm{L}$ at 10 or more years of age was considered a reasonable indicator of ovarian impair-

Optimal Pubertal Induction in Girls with TS
Table 1. Oral $17 \beta$-estradiol regimen for pubertal induction and first post-induction year (year 4), modified from Bannink et al. [23]

\begin{tabular}{lc}
\hline Year, months & Dose of estradiol, $\mu \mathrm{g} / \mathrm{kg} / \mathrm{day}$ \\
\hline $1(0-12)$ & 5 \\
$2(13-24)^{*}$ & 7.5 \\
$3(25-30)$ & 10 \\
$3(31-36)$ & 15 \\
$4(37-48)^{* *}$ & $20^{\dagger}$ \\
\hline
\end{tabular}

The dose is calculated according to body weight at the beginning of each year and given before sleep each night.

* Girls in whom low final height is anticipated may receive an extra 6 months of $7.5 \mu \mathrm{g} / \mathrm{kg} /$ day between Year 2 and Year 3 .

** Morning serum estradiol sample is recommended at the beginning of Year 4 . Note that the target range of $150-450 \mathrm{pmol} / \mathrm{L}$ shown in Table 2 [22] has been validated for transdermal but not oral estradiol administration.

$\dagger$ This post-induction dose equates to about $1 \mathrm{mg}$ daily.

ment requiring pubertal induction in girls with TS. However, it was accepted that the patient's clinician should decide whether to start pubertal induction at 11 years or later, to allow the possibility of spontaneous puberty to occur.

There was agreement that pubertal induction should be carried out over a 3-year period but that a faster induction period (e.g., 2 years) could be considered in girls who were older (e.g., $>13$ years) at the time of starting induction due to late diagnosis.

It was also agreed that both induction regimens should use $17 \beta$-estradiol rather than synthetic estrogens, partly for physiological reasons but also so that serum levels can be measured. Weight-based rather than fixed dosage was also agreed, consistent with other forms of paediatric endocrine replacement therapy such as thyroxine, GH and cortisol.

Adjusting dosage during induction by titrating serum estradiol level as described by Norjavaara et al. [21] was discussed but considered potentially difficult for some participating countries. However, at the beginning of year 4 when the adult estradiol dose had been reached, serum estradiol should be checked to enable dose modification. With transdermal oestrogen, a range of 150-450 pmol/L should be aimed for based on 159 healthy girls aged 16-19 years [22]. No such target range has been established with oral estrogen therapy, given the high levels of estrone, estrone-sulphate and total bioestrogen when the oral route is used. 
Fig. 1. Examples of how to cut different types of patches. The lines depict where to cut. After cutting the patch, the remaining pieces of the patch are placed in the original sachet, sealed by hand and stored at room temperature.

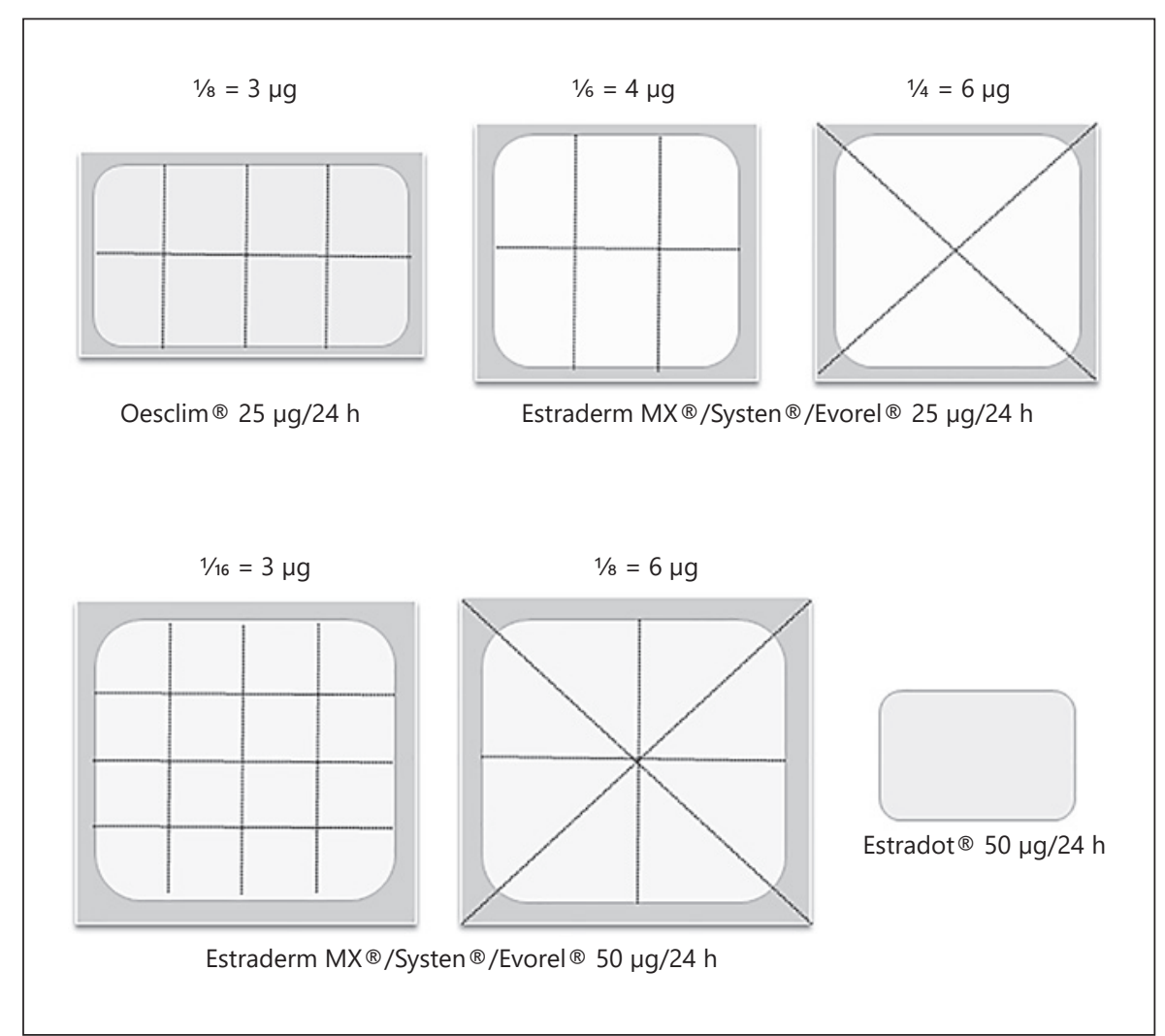

\section{Oral Induction of Puberty in TS (Table 1)}

Table 1 shows the agreed oral 3-year induction protocol together with a final (fourth) year, of maintenance treatment. The protocol is adapted from Dr. de Muinck Keizer-Schrama in the Netherlands and subsequently described by Bannink et al. [23]. Estradiol dose is based on body weight and is recalculated at the beginning of each year.

It was agreed that, where possible, $17 \beta$-estradiol be given in its micronized (e.g., Estrace) or hemihyrate (e.g., Cetura) form using $0.5 \mathrm{mg}$ tablets, which can be halved by the family. Alternatives include $17 \beta$-estradiol valerate (e.g., Climaval and Zumenon), since this ester is converted to $17 \beta$-estradiol in the liver, but these and other hemihyrate preparations (e.g., Elleste solo and Estrofem) are available only as $1 \mathrm{mg}$ tablets. Participating centres would therefore need either to order a $0.5 \mathrm{mg}$ preparation, or for their pharmacy to prepare a suitable dose from a $1 \mathrm{mg}$ tablet. Girls receiving $<0.25 \mathrm{mg}$ daily would need their medication prepared by the pharmacist. In patients requiring $\geq 0.25 \mathrm{mg}$ daily the dose would be rounded to the nearest $0.25 \mathrm{mg}$. Evening administration was recommended to mirror the transdermal regimen.
Girls who were markedly short, defined as $\leq 3$ standard deviations below the population mean, at the start of induction could be offered a slower induction adding in an extra 6 months of $7.5 \mu \mathrm{g} / \mathrm{kg} /$ day of $17 \beta$-estradiol between years 2 and 3. During the fourth year of maintenance treatment, estradiol dose will vary between 1 and $4 \mathrm{mg}$ daily, depending on patient sensitivity, most patients requiring at least $2 \mathrm{mg}$ daily.

\section{Transdermal Induction of Puberty in TS (Table 2 and}

Fig. 1)

Table 2 shows the agreed regimen, modified from the Swedish protocol described by Ankarberg-Lindgren et al. [15]. An overnight patch is applied for 10-12 $\mathrm{h}$ during the first 2 years of induction. Dosage is weight based and increased in accordance with weight at the clinic visit. Patches are applied on a healthy part of the skin (buttocks, belly or lower part of back), cutting the appropriate dose as shown in the Figure 1. A new patch is applied on a different part of the skin. During the third year of induction, the dose is split during the 24 -h period, cutting the desired patch piece in half to give 2 pieces, applying both pieces overnight then removing one in the morning. The 
Table 2. Protocol for three years of transdermal $17 \beta$-estradiol pubertal induction regimen and first post-induction year

\begin{tabular}{|c|c|c|c|c|c|}
\hline & Weight, kg & $50 \mu \mathrm{g}$ patch & $25 \mu \mathrm{g}$ patch & Duration of treatment & Instructions \\
\hline \multirow[t]{3}{*}{ Year $1^{*}$} & $<40 \mathrm{~kg}$ & $\begin{array}{l}\text { 1/16 of patch } \\
(3.1 \mu \mathrm{g})\end{array}$ & $\begin{array}{l}1 / 8 \text { of patch } \\
(3.1 \mu \mathrm{g})\end{array}$ & \multirow[t]{3}{*}{$\begin{array}{l}10-12 \mathrm{~h} \text { (overnight, to } \\
\text { the normal diurnal var }\end{array}$} & \\
\hline & $40-55$ & $\begin{array}{l}1 / 12 \text { of patch } \\
(4.2 \mu \mathrm{g})\end{array}$ & $\begin{array}{l}1 / 6 \text { of patch } \\
(4.2 \mu \mathrm{g})\end{array}$ & & \\
\hline & $>55$ & $\begin{array}{l}1 / 8 \text { of patch } \\
(6.2 \mu \mathrm{g})\end{array}$ & $\begin{array}{l}\text { 1/4 patch } \\
(6.2 \mu \mathrm{g})\end{array}$ & & \\
\hline \multirow[t]{3}{*}{ Year 2} & $<40 \mathrm{~kg}$ & $\begin{array}{l}1 / 8 \text { of patch } \\
(6.2 \mu \mathrm{g})\end{array}$ & $\begin{array}{l}1 / 4 \text { of patch } \\
(6.2 \mu \mathrm{g})\end{array}$ & \multirow[t]{3}{*}{ 10-12 h (overnight) } & \\
\hline & $40-55$ & $\begin{array}{l}1 / 6 \text { of patch } \\
(8.3 \mu \mathrm{g})\end{array}$ & $\begin{array}{l}1 / 3 \text { patch } \\
(8.3 \mu \mathrm{g})\end{array}$ & & \\
\hline & $>55$ & $\begin{array}{l}1 / 4 \text { of patch } \\
(12.5 \mu \mathrm{g})\end{array}$ & $\begin{array}{l}1 / 2 \text { patch } \\
(12.5 \mu \mathrm{g})\end{array}$ & & \\
\hline \multirow[t]{3}{*}{ Year 3} & $<50 \mathrm{~kg}$ & $\begin{array}{l}1 / 3 \text { of patch } \\
(16.7 \mu \mathrm{g})\end{array}$ & $\begin{array}{l}2 / 3 \text { of patch } \\
(16.7 \mu \mathrm{g})\end{array}$ & & \multirow{3}{*}{$\begin{array}{l}\text { Cut the desired dose into two } \\
\text { halves; attach both parts to the } \\
\text { skin in the evening. After 10-12 h } \\
\text { (overnight) remove one part, } \\
\text { keep the second part during the } \\
\text { day. Remove the second part } \\
\text { in the evening, before evening } \\
\text { application of a new pair of } \\
\text { patches. This results in a diurnal } \\
\text { dose variation, with higher dose } \\
\text { nighttime }\end{array}$} \\
\hline & $50-65$ & $\begin{array}{l}3 / 8 \text { patch } \\
(18.8 \mu \mathrm{g})\end{array}$ & $\begin{array}{l}3 / 4 \text { patch } \\
(18.8 \mu \mathrm{g})\end{array}$ & & \\
\hline & $>65$ & $\begin{array}{l}1 / 2 \text { of patch } \\
(25 \mu \mathrm{g})\end{array}$ & $\begin{array}{l}1 \text { patch } \\
(25 \mu \mathrm{g})\end{array}$ & & \\
\hline $\begin{array}{l}\text { Year } 4^{* *} \\
\text { Post- } \\
\text { induction } \\
\text { dose }\end{array}$ & $\begin{array}{l}\text { Not } \\
\text { applicable }\end{array}$ & \multicolumn{2}{|c|}{$\begin{array}{l}50-75(-100) \mu \mathrm{g} / 24 \mathrm{~h} \\
(\text { Often } \sim 1 \mu \mathrm{g} / \mathrm{kg} / 24 \mathrm{~h})\end{array}$} & & $\begin{array}{l}\text { Patch continuously attached to } \\
\text { the skin. Apply whole patch } 3 \\
\text { times weekly, that is, changing } \\
\text { after } 2-3 \text { days. Serum sample } \\
\text { for estradiol target to be drawn in } \\
\text { the morning after the previous } \\
\text { evening's dose, target range } \\
150-450 \mathrm{pmol} / \mathrm{L}\end{array}$ \\
\hline
\end{tabular}

The dose at the beginning of each year is calculated according to body weight. Year 4 corresponds to post-induction dose.

* Girls in whom low final height is anticipated may receive an extra 6 months of the Year 1 dose.

** Serum estradiol sample to be drawn at start of Year 4 in the morning, target range 150-450 pmol/L (see Fanelli et al. [22]).

stability at 21 and $35^{\circ} \mathrm{C}$ and uniformity of estradiol distribution has recently been demonstrated for Systen (Evorel), Estraderm and Oesclim (50,50, and $25 \mu \mathrm{g}$ per $24 \mathrm{~h})$ patches when cut into 8 pieces [24].

\section{Feedback on Protocols by Parent Support Groups}

Both protocols were sent for scrutiny by the TS Support Societies of 3 countries - United Kingdom, Netherlands and Poland - with executive officers disseminating the information among members. All 3 groups reported favourable feedback, with none considering either regime too difficult to administer.

\section{Oral Progesterone Administration}

A progesterone rather than testosterone-derived or weakly androgenic preparation such as norethisterone was suggested. Recommended oral progestogens were dydrogesterone (9 $\beta, 10 \alpha$-pregna-4,6-diene-3,20-dione) 
Table 3. Measurements recommended to be taken before, during and at the end of pubertal induction with either transdermal or oral $17 \beta$-estradiol grouped according to priority - essential, desirable and research-based

\begin{tabular}{lllll}
\hline Variable & $\begin{array}{l}\text { Before/within } \\
6 \text { months of } \\
\text { induction }\end{array}$ & $\begin{array}{l}\text { Years 1 } \\
\text { and 2 }\end{array}$ & Year 3 & \\
& & & \\
\hline
\end{tabular}

\section{Essential}

Karyotype

Auxology

Height, $\mathrm{cm}$

Weight, $\mathrm{kg}$

Height velocity, $\mathrm{cm} /$ year

Measured parental heights

Breast and pubic hair stage (1-5)
Systolic and diastolic blood pressure, $\mathrm{mm} \mathrm{Hg}$

$\mathrm{x}$

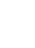

$\begin{array}{lll}x & x & x\end{array}$

$\mathrm{x}-\mathrm{x}-\mathrm{x}$

$\begin{array}{lll}\mathrm{x} & \mathrm{x} \\ \mathrm{x} & \mathrm{x}\end{array}$

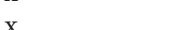

$\mathrm{x}$

$\mathrm{x}$

$\mathrm{x}$

Height velocity to be calculated using 12 ( \pm 1 month) interval; and GH responsiveness from height/weight 1 year before, at the start of, and 1 year after starting GH

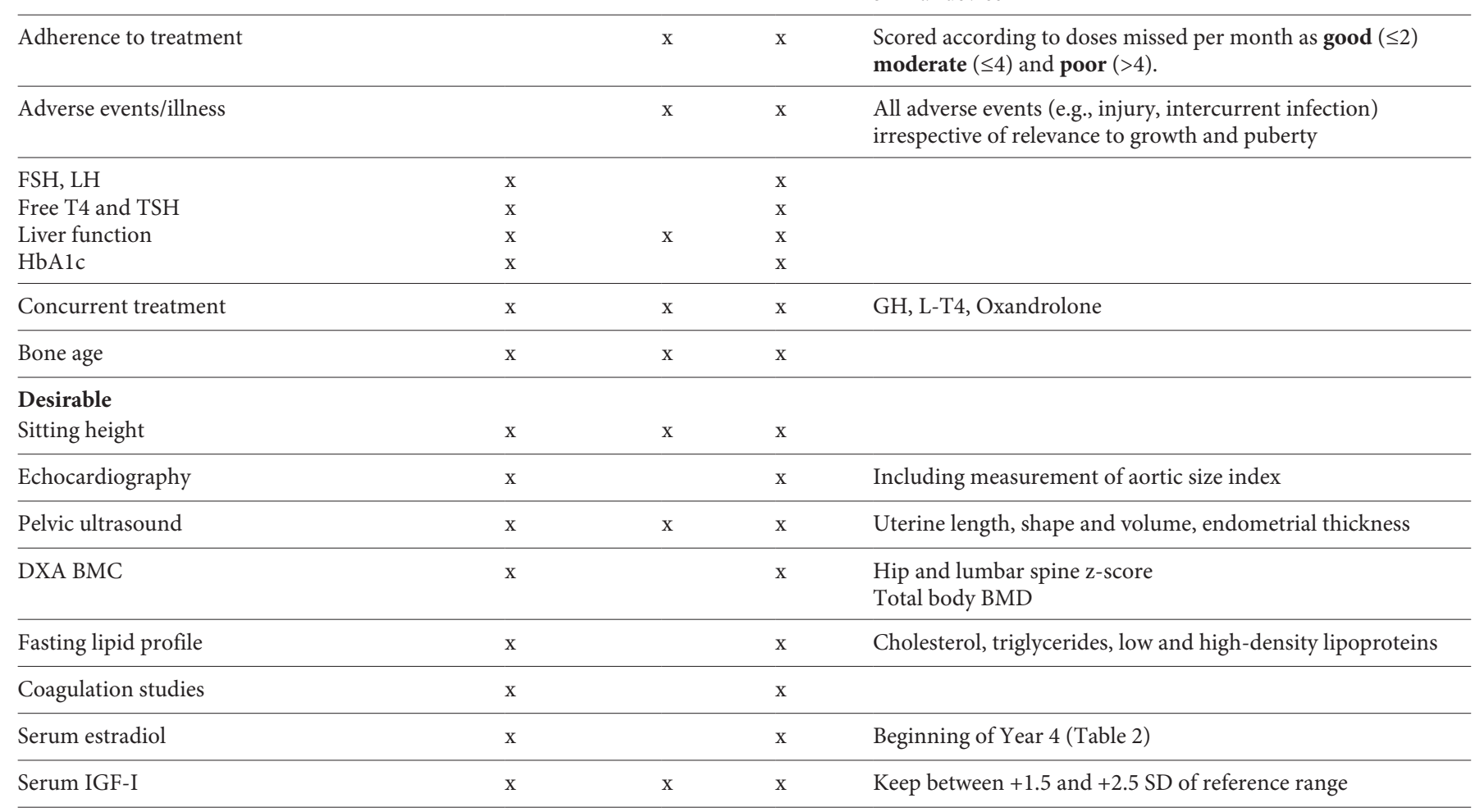

\section{Selected cases only}

$24 \mathrm{~h}$ continuous ambulatory blood pressure

Fasting blood glucose and insulin

$\begin{array}{ll}\mathrm{x} & \mathrm{x} \\ \mathrm{x} & \mathrm{x}\end{array}$

FSH, follicle stimulating hormone; LH, luteinising hormone; fT4, free thyroxine; TSH, thyroid stimulating hormone; DXA, dual X-ray absorptiometry; $\mathrm{BMC}$, bone mineral content; BMD, bone mineral density; GH, growth hormone; L-T4, levo-thyroxine.

$10 \mathrm{mg}$; micronised progesterone $100 \mathrm{mg}$; and medroxyprogesterone acetate $5-10 \mathrm{mg}$ [13]. In keeping with the Cincinnati guidelines [12] a duration of 10 days each calendar month was proposed.

In contrast to the Cincinnati guidelines [12], advice from gynaecology and reproductive endocrine colleagues indi- cated that oral progesterone should not be given pre-emptively after 2 years, or automatically at the time of the first breakthrough bleed. Instead, to allow maximum time for uterine and breast development with unopposed estrogen, it was recommended that pubertal staging and where possible pelvic ultrasound examination should be carried out 
at the time of bleeding so that uterine size and endometrial thickness could be determined. In cases where the endometrium is still thin and the uterus relatively small, progesterone treatment should be deferred, but introduced if ultrasound shows a mature uterus with thick endometrium.

\section{Concurrent Treatment with GH and Oxandrolone}

It was anticipated that most girls would be receiving both GH therapy as well as estradiol and that participating centres would give standard GH doses for TS - 1.4 $\mathrm{mg} / \mathrm{m}^{2} /$ day, equivalent to $50-65 \mu \mathrm{g} / \mathrm{kg} /$ day [25] and modified according to individual GH responsiveness. It was agreed that insulin-like growth factor-1 should be measured at the beginning of induction and then annually as per the Cincinnati guidelines [12], aiming for values between +1.5 and +2.5 SD score (SDS) and modifying $\mathrm{GH}$ dosage to keep insulin-like growth factor-1 below +3 SDS.

Currently Oxandrolone is not manufactured in Europe. It is available to import from the United States of America and Australia but expensive. Consequently, although shown to improve adult height in TS in the dose of $0.05 \mathrm{mg} / \mathrm{kg} /$ day (maximum dose $2.5 \mathrm{mg}$ daily) [25], Oxandrolone tends to be reserved for girls who respond poorly to GH despite good compliance [26]. The group agreed that no standard approach to either GH or Oxandrolone could be imposed and that variations in these factors would need to be factored into the data analysis.

\section{Data Collection before and during Pubertal Induction (Table 3)}

Table 3 shows the recommended information to be collected before, during and at the end of pubertal induction, categorized as essential, desirable and in selected situations. Given that height gain during induction is the agreed primary outcome measure, previous height and weight data from 1 year before, at the time of and 1 year after the start of GH treatment and at least yearly thereafter, together with GH dose and possible oxandrolone treatment, are required to assess $\mathrm{GH}$ responsiveness [27, 28], while height and weight (and GH dose) at the start of pubertal induction should be obtained not more than 1 month before starting estradiol.

Echocardiogram to define the anatomy of the heart and great vessels, with measurement of aortic root diam- eter and aortic size index, was considered highly desirable but dependent on local availability. Annual liver function tests were recommended, to compare outcome with the oral and transdermal routes. A fasting lipid profile and coagulation studies before and after induction, were also considered desirable. Concerning frequency of clinic attendance, TSWG agreed that girls should be seen every 3-4 months and at least 6-monthly, measured by a trained observer using standardised and well-maintained equipment. Self-reported adherence could be scored as good, moderate or poor according to the number of doses missed per month (Table 3).

Finally, it was agreed that all adverse events including minor injury, inter-current infection, middle ear problems and gastrointestinal symptoms, should be reported by the family at each visit and summarised at the end of each year by the clinician.

\section{Evaluation of Outcome (Table 4)}

Together with the primary outcome measure, agreed secondary outcome measures included: adult height, given as both centimetres and as Turner-specific SDS [29], change in height SDS, pubertal maturation tempo, breast development and cardiovascular health - systolic and diastolic blood pressure and change in aortic root diameter/ size index. Patient satisfaction and acceptability (related to adherence) were also considered important outcomes. A Turner-specific quality-of-life questionnaire is currently unavailable, but it was agreed that this could be developed during the proposed study and piloted in a subgroup of patients.

\section{Statistical Aspects and Data Analysis}

Power calculation: Analysis of anonymised data from the UK clinical trial of Gault et al. [25] was carried out to determine height gain during 3 years of pubertal induction in TS girls who were treated with a consistent dose of GH. In 77 of 92 girls in whom data were available, mean (SD) height gain during this period was $12.2(3.5) \mathrm{cm}$. A mean difference of $2.5 \mathrm{~cm}$ between transdermal and oral regimens was considered clinically significant, giving a fractional effect size (f) of $2.5 / 3.5=0.71$. Using the Lehr formula where $n=21 / \mathrm{f}^{2}$ gives the number of patients in each arm of the study required for $90 \%$ power at the $5 \%$ level [30], the number would be 42 . Given the covariates including age at diagnosis, karyotype, age at starting GH 
Table 4. Outcome measures to be analysed at the end of a 3-year pubertal induction period in girls with Turner syndrome using either a transdermal or oral $17 \beta$-estradiol regime approved by the TSWG of ESPE

Primary outcome measure

Height gain in centimetres during 3 years of pubertal induction

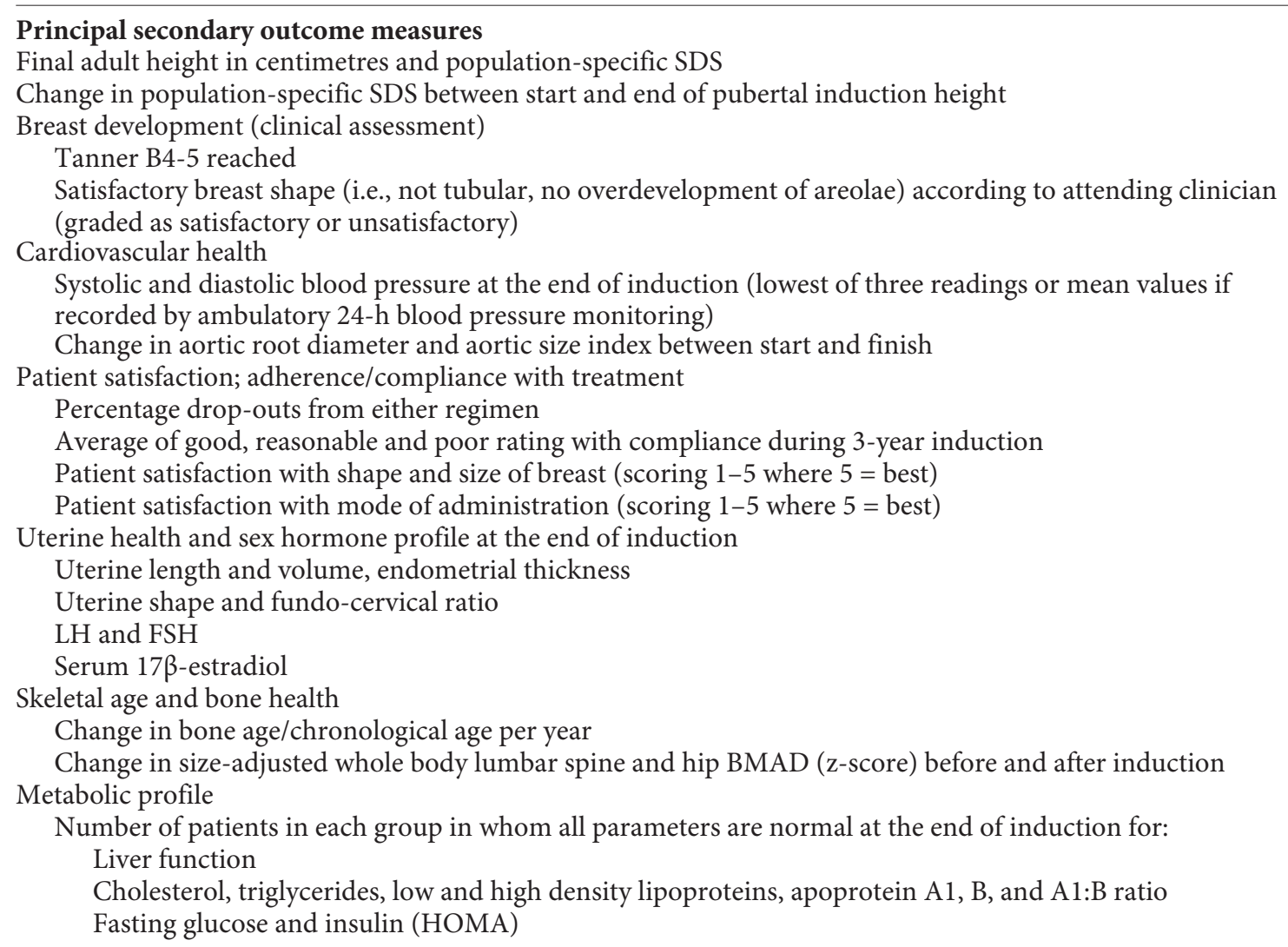

TSWG, Turner Syndrome Working Group; ESPE, European Society for Paediatric Endocrinology; SDS, SD score; BMAD, bone mineral areal density.

therapy, differing dosage regimens, and use or not of Oxandrolone amongst the enrolled patients, a recruitment target of twice the power calculation, that is, up to 84 in each treatment arm, was considered desirable to be able to adjust for potential confounding factors.

\section{Data Analysis}

This will entail examining the demographics of patients choosing either oral or transdermal estradiol preparations and looking for differences at baseline, which could have impact on outcome at follow-up. The number of patients in each treatment arm, together with their centres and countries will be recorded. Measuring adherence to each of the treatment arms will give valuable informa- tion, as would the reasons for drop-out or loss to followup.

It is anticipated that propensity score matching will be implemented to reduce any bias due to confounding factors. These include 45,X karyotype, mid-parental height, height at the beginning of pubertal induction, duration of prior $\mathrm{GH}$ treatment, $\mathrm{GH}$ responsiveness and treatment or not with oxandrolone. Directed Acyclic Graphs will be used to establish the minimally sufficient set of confounders for each outcome parameter [31], which will be entered into multivariable regression models. 


\section{Discussion}

This pragmatic proposed prospective cohort study is designed to be available to all countries in which the requisite medications for at least one of the pubertal induction protocols are available. The relevant legal and ethical aspects would need to be followed by the participating countries, but there should be no major obstacles in obtaining approval, given that the study proposal involves offering a choice of protocols, which have been agreed as part of good clinical practice to patients who require estrogen treatment.

The transdermal protocol proposed in this study attempts to mimic normal puberty as closely as possible, including the diurnal variation reported in healthy girls [21]. While it may seem more complicated than elsewhere $[12,13]$, it has been routinely used in Sweden over the past decade and is well received by families [15]. Since pieces from 1 patch can be used and stored for up to 30 days with no decrease in pharmacological activity [24], the agreed transdermal regimen is potentially cheaper than previously.

Concerning oral estradiol induction, divisible $0.5 \mathrm{mg}$ tablets are recommended. These are available in the Netherlands as Cetura (17 $\beta$-estradiol hemihydrate) and in the United States as Estrace (micronised $17 \beta$-estradiol), while elsewhere only $1 \mathrm{mg}$ preparations of $17 \beta$-estradiol as valerate or hemihydrate are available. Thus, the challenge to clinicians and pharmacists, whether participating in the proposed study or not, is to deliver initial oral $17 \beta$-estradiol doses of $0.25 \mathrm{mg}$ daily or less which comply with the Cincinnati guidelines [12].

Of note, there are inherent differences between the two agreed regimens being compared, both derived from current clinical practice and agreed upon by clinicians active in the clinical care of girls with TS. The oral and transdermal regimens differ not only in the mode of estrogen delivery into the blood stream but also in diurnal variation; half-life of estrogen; and estradiol to estrone conversion. Any attempt to render estrogen dosage to the tissues comparable using the agreed protocols would be hard to achieve, given the marked difference in circulating estradiol levels with the transdermal and oral routes [15, 32]. This is attributable to assay differences, with the direct immunoassay overestimating estradiol levels within the lower range of concentration [33, 34]; and to significant cross reaction (as much as 10\%) with the high levels of estrone produced with oral estradiol therapy. There is also considerable inter-individual variation in response to both oral and transdermal estradiol, with adult replace-

Optimal Pubertal Induction in Girls with TS ment doses ranging between 1-4 mg and 50-100 $\mu \mathrm{g}$ using oral and transdermal delivery.

While basal serum FSH is valuable in deciding which TS girls need pubertal induction at 11 years, the cut-off level is contentious. FSH and LH present a biphasic pattern between birth and adolescence, with values before 10 years of age sometimes low even in girls with primary ovarian failure $[35,36]$. Recent work from Poland suggests that FSH levels of $>6.5 \mathrm{IU} / \mathrm{L}$ in mid-childhood are predictive of the need for future estrogen replacement therapy [37]. It is reasonable to begin induction at 11 years in girls with FSH $>10$ IU/L, rather than risking delayed and/or incomplete pubertal development.

The tempo of pubertal induction is also debatable. Cincinnati guidelines suggest $2-3$ years [12] but we consider less than 3 years to be unphysiological in allowing insufficient time for pubertal growth and development. In exceptional circumstances, for example, girls aged $>15$ at presentation, this period could be shortened.

The evidence for optimal timing, choice of preparation and number of days of progestogen administration are lacking. While Cincinnati guidelines recommend adding progesterone once breakthrough bleeding occurs or after 2 years of estrogen treatment [12], we suggest assessing pubertal and uterine status at the time of breakthrough bleeding. If ultrasound shows an undeveloped uterus and thin endometrial lining (indicating insufficient estradiol) unopposed estradiol treatment is continued, but if the uterus is mature with endometrial thickening (indicating sufficient estradiol) progestogen is introduced. The lack of evidence for preferring 5, 7, 10, and 14 days of administration has resulted in a pragmatic recommendation of 10 days treatment, in keeping with the Cincinnati guidelines [12].

In deciding on which aspects of growth and puberty should be monitored during pubertal induction, the TSWG was careful to take into consideration the varying availability of resources within and beyond Europe as well as the clinical need to carry out certain investigations. Assessment of growth, pubertal status, and blood pressure are within the remit of all clinicians, as are the overseeing of pubertal development and adjustment of estrogen doses during the induction period. Annual measurement of thyroid function is mandatory, given the increased prevalence of autoimmune thyroiditis in TS, affecting 15 out of 86 (17.4\%) of girls in a recent study [38]. Other investigations, which are less widely available, include sitting height, echocardiography, pelvic ultrasound and assessment of bone mineral density. From the safety aspect it was agreed that liver function should be assessed before and after induction in all cases, and lipid and coagulation profile where 
possible. In general, the group tried to recommend monitoring in compliance with the Cincinnati guidelines [12].

By setting standards and outcomes in advance, important differences between the oral and transdermal protocols can be evaluated. In our study proposal, the primary outcome measure chosen was that of growth. Also, for the first time, issues of patient acceptability and adherence are addressed. We hope the results of the proposed study will facilitate decisions about future patient care and will serve as a model for the study of other rare childhood disorders.

\section{Acknowledgements}

The authors gratefully acknowledge the help from Mrs. Arlene Smyth and the TS Support Society, UK as well as the Polish and Dutch Support groups for their help and support. We also thank Professor Gerry Conway and Dr. Melanie Davies from University College London Hospitals for their help with the manuscript, particularly concerning the section on progesterone treatment; and Ms. Deborah Ridout from University College London, UCL Great Ormond Street Institute of Child Health, UK for help with the power calculation.

\section{Disclosure Statement}

The authors declare that they have no conflicts of interest to disclose.

\section{ESPE TS Working Group}

The Turner Working Group members are Muzsnai Ágota (Hungary), Natallia Akulevich (Belarus), Kerstin Albertsson-Wikland (Sweden), Carina Ankarberg-Lindgren (Sweden), Ece Böber (Turkey), Atilla Buyukgebiz Turkey), Jean-Claude Carel (France), Catherine Dacou-Voutetakis (Greece), Sabine de Muinck KeizerSchrama (Netherlands), Malcolm Donaldson (UK), Emma Jane Gault (United Kingdom), Lucio Ghizzoni (Italy), Christina Kanaka-Gantenbein (Greece), Aneta Gawlik (Poland), Berit Kristrom (Sweden), Alexander Kurtev (Bulgaria), Ewa Malecka-Tendera (Poland), Laura Mazzanti (Italy), Ensio Norjavaara (Sweden), Jadranka Popovic (USA), Michael Ranke (Germany), Theo Sas (Netherlands), Agnes Sallai (Hungary), Stefano Stagi (Italy), Janielle van Alfen-van der Velden (Netherlands), Siska Verlinde (Belgium), Malgorzata Wasniewska (Italy), Delphine Zenaty (France), Nehama Zuckerman-Levin (Israel).

\section{References}

1 Donaldson MD, Gault EJ, Tan KW, Dunger DB. Optimising management in Turner syndrome: from infancy to adult transfer. Arch Dis Child. 2006 Jun;91(6):513-20.

2 Ranke MB, Saenger P. Turner's syndrome. Lancet. 2001 Jul;358(9278):309-14.

3 Pasquino AM, Passeri F, Pucarelli I, Segni M, Municchi G; Italian Study Group for Turner's Syndrome. Spontaneous pubertal development in Turner's syndrome. J Clin Endocrinol Metab. 1997 Jun;82(6):1810-3.

4 Gravholt CH, Juul S, Naeraa RW, Hansen J. Morbidity in Turner syndrome. J Clin Epidemiol. 1998 Feb;51(2):147-58.

5 Schoemaker MJ, Swerdlow AJ, Higgins CD, Wright AF, Jacobs PA; United Kingdom Clinical Cytogenetics Group. Mortality in women with turner syndrome in Great Britain: a national cohort study. J Clin Endocrinol Metab. 2008 Dec;93(12):4735-42.

6 Carlson M, Silberbach M. Dissection of the aorta in Turner syndrome: two cases and review of 85 cases in the literature. J Med Genet. 2007 Dec;44(12):745-9.

7 Ostberg JE, Donald AE, Halcox JP, Storry C, McCarthy C, Conway GS. Vasculopathy in Turner syndrome: arterial dilatation and intimal thickening without endothelial dysfunction. J Clin Endocrinol Metab. 2005 Sep;90(9):5161-6.

8 Ho VB, Bakalov VK, Cooley M, Van PL, Hood MN, Burklow TR, et al. Major vascular anomalies in Turner syndrome: prevalence and magnetic resonance angiographic features. Circulation. 2004 Sep;110(12):1694-700.
9 Wong SC, Cheung M, Zacharin M. Aortic dilatation and dissection in Turner syndrome: what we know, what we are unclear about and what we should do in clinical practice? Int J Adolesc Med Health. 2014;26(4):469-88.

10 Calcaterra V, Brambilla P, Maffè GC, Klersy C, Albertini R, Introzzi F, et al. Metabolic syndrome in Turner syndrome and relation between body composition and clinical, genetic, and ultrasonographic characteristics. Metab Syndr Relat Disord. 2014 Apr;12(3):159-64.

11 Webber L, Davies M, Anderson R, Bartlett J, Braat D, Cartwright B, et al.; European Society for Human Reproduction and Embryology (ESHRE) Guideline Group on POI. ESHRE Guideline: management of women with premature ovarian insufficiency. Hum Reprod. 2016 May;31(5):926-37.

12 Gravholt $\mathrm{CH}$, Andersen NH, Conway GS, Dekkers OM, Geffner ME, Klein KO, et al.; International Turner Syndrome Consensus Group. Clinical practice guidelines for the care of girls and women with Turner syndrome: proceedings from the 2016 Cincinnati International Turner Syndrome Meeting. Eur J Endocrinol. 2017 Sep;177(3):G170 .

13 Matthews D, Bath L, Högler W, Mason A, Smyth A, Skae M. Hormone supplementation for pubertal induction in girls. Arch Dis Child. 2017 Oct;102(10):975-80.

14 Christin-Maitre S. Use of Hormone Replacement in Females with Endocrine Disorders. Horm Res Paediatr. 2017;87(4):215-23.
15 Ankarberg-Lindgren C, Kriström B, Norjavaara E. Physiological estrogen replacement therapy for puberty induction in girls: a clinical observational study. Horm Res Paediatr. 2014;81(4):239-44.

16 Langrish JP, Mills NL, Bath LE, Warner P, Webb DJ, Kelnar CJ, et al. Cardiovascular effects of physiological and standard sex steroid replacement regimens in premature ovarian failure. Hypertension. 2009 May;53(5):80511.

17 O’Donnell RL, Warner P, Lee RJ, Walker J, Bath LE, Kelnar CJ, et al. Physiological sex steroid replacement in premature ovarian failure: randomized crossover trial of effect on uterine volume, endometrial thickness and blood flow, compared with a standard regimen. Hum Reprod. 2012 Apr;27(4):1130-8.

18 Crofton PM, Evans N, Bath LE, Warner P, Whitehead TJ, Critchley HO, et al. Physiological versus standard sex steroid replacement in young women with premature ovarian failure: effects on bone mass acquisition and turnover. Clin Endocrinol (Oxf). 2010 Dec; 73(6):707-14.

19 Nabhan ZM, Dimeglio LA, Qi R, Perkins SM, Eugster EA. Conjugated oral versus transdermal estrogen replacement in girls with Turner syndrome: a pilot comparative study. J Clin Endocrinol Metab. 2009 Jun;94(6):2009-14.

20 MacLean N, Harnden DG, Brown WM, Bond J, Mantle DJ. Sex-chromosome abnormalities in newborn babies. Lancet. 1964 Feb;1(7328): 286-90. 
21 Norjavaara E, Ankarberg C, Albertsson-Wikland K. Diurnal rhythm of 17 beta-estradiol secretion throughout pubertal development in healthy girls: evaluation by a sensitive radioimmunoassay. J Clin Endocrinol Metab. 1996 Nov;81(11):4095-102.

22 Fanelli F, Gambineri A, Belluomo I, Repaci A, Di Lallo VD, Di Dalmazi G, et al. Androgen profiling by liquid chromatography-tandem mass spectrometry (LC-MS/MS) in healthy normal-weight ovulatory and anovulatory late adolescent and young women. J Clin Endocrinol Metab. 2013 Jul;98(7):3058-67.

23 Bannink EM, van Sassen C, van Buuren S, de Jong FH, Lequin M, Mulder PG, et al. Puberty induction in Turner syndrome: results of oestrogen treatment on development of secondary sexual characteristics, uterine dimensions and serum hormone levels. Clin Endocrinol (Oxf). 2009 Feb;70(2):265-73.

24 Ankarberg-Lindgren C, Gawlik A, Kriström B, Mazzanti L, Ruijgrok EJ, Sas TC. Estradiol matrix patches for pubertal induction: stability of cut pieces at different temperatures. Endocr Connect. 2019 Mar;8(4):EC-19-0025.R1.

25 Gault EJ, Perry RJ, Cole TJ, Casey S, Paterson WF, Hindmarsh PC, et al.; British Society for Paediatric Endocrinology and Diabetes. Effect of oxandrolone and timing of pubertal induction on final height in Turner's syndrome: randomised, double blind, placebo controlled trial. BMJ. 2011;342:d1980.

26 Sas TC, Gault EJ, Bardsley MZ, Menke LA, Freriks K, Perry RJ, et al. Safety and efficacy of oxandrolone in growth hormone-treated girls with Turner syndrome: evidence from recent studies and recommendations for use. Horm Res Paediatr. 2014;81(5):289-97.
27 Ranke MB, Lindberg A, Chatelain P, Wilton $\mathrm{P}$, Cutfield W, Albertsson-Wikland K, et al.; KIGS International Board. Kabi International Growth Study. Prediction of long-term response to recombinant human growth hormone in Turner syndrome: development and validation of mathematical models. KIGS International Board. Kabi International Growth Study. J Clin Endocrinol Metab. 2000 Nov; 85(11):4212-8.

28 Kriström B, Dahlgren J, Niklasson A, Nierop AF, Albertsson-Wikland K. The first-year growth response to growth hormone treatment predicts the long-term prepubertal growth response in children. BMC Med Inform Decis Mak. 2009 Jan;9:1.

29 Rongen-Westerlaken C, Corel L, van den Broeck J, Massa G, Karlberg J, AlbertssonWikland $\mathrm{K}$, et al. Reference values for height, height velocity and weight in Turner's syndrome. Swedish Study Group for GH treatment. Acta Paediatr. 1997 Sep;86(9):937-42.

30 Cole TJ. Sampling, study size and power. In Margetts BM, Nelson M, editors. Design concepts in nutritional epidemiology. 2nd ed. Oxford: Oxford University Press; 1997. pp. 64-86.

31 Krieger N, Davey Smith G. The tale wagged by the DAG: broadening the scope of causal inference and explanation for epidemiology. Int J Epidemiol. 2016 Dec;45(6):1787-808.

32 Taboada M, Santen R, Lima J, Hossain J, Singh R, Klein KO, et al. Pharmacokinetics and pharmacodynamics of oral and transdermal $17 \beta$ estradiol in girls with Turner syndrome. J Clin Endocrinol Metab. 2011 Nov; 96(11):3502-10.
33 Stanczyk FZ, Jurow J, Hsing AW. Limitations of direct immunoassays for measuring circulating estradiol levels in postmenopausal women and men in epidemiologic studies. Cancer Epidemiol Biomarkers Prev. 2010 Apr;19(4):903-6.

34 Ankarberg-Lindgren C, Norjavaara E. A purification step prior to commercial sensitive immunoassay is necessary to achieve clinical usefulness when quantifying serum 17betaestradiol in prepubertal children. Eur J Endocrinol. 2008 Jan;158(1):117-24.

35 Hagen CP, Main KM, Kjaergaard S, Juul A. $\mathrm{FSH}, \mathrm{LH}$, inhibin $\mathrm{B}$ and estradiol levels in Turner syndrome depend on age and karyotype: longitudinal study of 70 Turner girls with or without spontaneous puberty. Hum Reprod. 2010 Dec;25(12):3134-41.

36 Conte FA, Grumbach MM, Kaplan SL. A diphasic pattern of gonadotropin secretion in patients with the syndrome of gonadal dysgenesis. J Clin Endocrinol Metab. 1975 Apr; 40(4):670-4.

37 Hankus M, Soltysik K, Szeliga K, Antosz A, Drosdzol-Cop A, Wilk K, et al. Prediction of Spontaneous Puberty in Turner Syndrome Based on Mid-Childhood Gonadotropin Concentrations, Karyotype, and Ovary Visualization: A Longitudinal Study. Horm Res Paediatr. 2018;89(2):90-7.

38 Gawlik A, Gawlik T, Januszek-Trzciakowska A, Patel H, Malecka-Tendera E. Incidence and dynamics of thyroid dysfunction and thyroid autoimmunity in girls with Turner's syndrome: a long-term follow-up study. Horm Res Paediatr. 2011;76(5):31420. 